Article

\title{
Particle Size and Pre-Treatment Effects on Polystyrene Microplastic Settlement in Water: Implications for Environmental Behavior and Ecotoxicological Tests
}

\author{
Lars Eitzen $^{1, *}$, Aki Sebastian Ruhl ${ }^{1,2}$ (1) and Martin Jekel ${ }^{1}$ \\ 1 Technische Universität Berlin, Sekr. KF 4, Straße des 17, Juni 135, D-10623 Berlin, Germany; \\ akisebastian.ruhl@uba.de (A.S.R.); martin.jekel@tu-berlin.de (M.J.) \\ 2 German Environment Agency (UBA), Section II 3.1, Schichauweg 58, D-12307 Berlin, Germany \\ * Correspondence: lars.eitzen@tu-berlin.de
}

Received: 19 October 2020; Accepted: 4 December 2020; Published: 8 December 2020

check for updates

\begin{abstract}
Microplastic (MP) particle dispersions used in many recent publications covering adsorption or toxicological studies are not characterized very well. The size distribution of polydisperse dispersions is highly dependent on the agglomeration processes and influences experimental outcomes. Therefore, pre-treatment is a prerequisite for reproducibility. In this study, manual/automated shaking and ultrasonic treatment as different mechanical dispersion techniques were applied for the dispersion of cryomilled polystyrene (PS). Particle numbers and size distribution of dispersions were analyzed by a light extinction particle counter and the dispersion efficiency $\left(E_{D}\right)$ as the ratio between calculated volume and theoretical volume of suspended particles was used to compare techniques. PS dispersions $(20 \mathrm{mg} / \mathrm{L})$ treated for $90 \mathrm{~min}$ in an ultrasonic bath $(120 \mathrm{~W}, 35 \mathrm{kHz})$ were evenly dispersed with a particle concentration of 140,000 particles $/ \mathrm{mL}$ and a high reproducibility (rel. SD $=2.1 \%, n=6)$. Automated horizontal shaking for $754 \mathrm{~h}(250 \mathrm{rpm})$ reached similar particle numbers $(122,000 / \mathrm{mL})$ but with a lower reproducibility (rel. SD $=9.1 \%, n=6)$. Manual shaking by hand dispersed the lowest number of particles $(55,000 / \mathrm{mL})$ and was therefore found to be unsuitable to counteract homo-agglomeration. $\mathrm{E}_{\mathrm{D}}$ was calculated as $127 \%, 104 \%$ and $69 \%$ for ultrasonic treatment, horizontal shaking and manual shaking, respectively, showing an overestimation of volume assuming spherical shaped particles.
\end{abstract}

Keywords: microplastics; polystyrene; dispersion; ultrasonic; deagglomeration; size distribution; sample preparation

\section{Introduction}

A great emphasis in microplastic (MP) research is put on the spatial distribution, transport and behavior of microplastics in water. The interactions of MP in the aqueous phase are numerous: leaching of potentially toxic additives, adsorption of organic compounds and metals to MP and toxicological effects on organisms are being investigated. With a few exceptions, all these studies use artificial MP dispersions to extrapolate laboratory findings to environmental behavior. For this reason, meaningful results require attention during the preparation of MP dispersions.

MP exposure experiments conducted with only a few details on applied mass, particle size distribution and concentration are hard to compare [1]. Prerequisites have been formulated for particle characterization used in toxicology studies regarding surface area or size distribution but also homogeneity of dispersion [2,3]. Only fully dispersed, stable dispersions with most particles existing separately allow for correct extrapolations of mass/number concentration effects. Dispersion stability is linked to particle size and specific surface area. However, pristine polymer particles as used in many 
studies are highly hydrophobic and poorly wettable if not chemically stabilized or further processed [4]. Depending on the material type and applied concentration of these particles, attachment to laboratory glassware, accumulation at the liquid-gas interface, and formation of homo-agglomerates are the consequences [5]. This reduces the availability of particles to participate in experiments and can strongly bias outcomes. The OECD Guideline concerning stability of nanomaterials highlights the dispersion stability as an important parameter affecting the environmental behavior of nanomaterials (with nanoplastics already being studied by some research groups) [6]. In many cases, surfactants such as sodium dodecyl sulfate or polysorbate (Tween) 20 or 80 are used and commercial particle dispersions are thereby commonly stabilized [7,8]. Surfactants are also added during the synthesis of MP which could alter the surface characteristics and thus the adsorption process [8,9]. Nevertheless, surfactants can also bias experiments: Renzi et al. [10] recorded a higher mortality and immobilization in toxicological experiments with MP when the surfactant Triton X-100 was used. The surfactant itself had negative effects on the organisms but the more stable dispersion of particles could also lead to increased ingestion and toxicity. Xia et al. [11] reported the effect of non-ionic surfactants on the sorption of organic pollutants onto microplastics. Natural organic matter (NOM) is also used in some studies to stabilize MP and mimic environmental conditions, but the effect of NOM on dispersion stability has not been fully resolved yet. Reported results indicate a stabilizing as well as no effect using NOM standard samples from the International Humic Substances Society (IHSS) in MP dispersions [12-16].

Oxidation of MP surfaces as an effect of weathering processes increases polarity, hydrophilicity and induces charge $[17,18]$. Artificial weathering can be achieved by UV photodegradation or chemical oxidation using hydrogen peroxide or ozone. Van der Esch used an alkaline oxidation with potassium hydroxide to simultaneously fragment and oxidize polystyrene (PS), polyethylene terephthalate (PET) and polyactic acid (PLA) polymers to obtain a stable dispersion [3]. The advantage of surface activation lies in the mode of stabilization which can closely resemble environmental weathering processes and thus create more realistic scenarios. Artificial weathering, however, is a time-consuming process, especially when using UV radiation. Ozone has been applied to stabilize PS particles, but the oxidation caused a size reduction of particles and a fraction of PS was dissolved [5].

The agglomeration behavior of dispersions has already been broadly studied for nanoparticles [19,20], with a focus on ecological investigations [21]. Pre-treatment for deagglomeration is an important step to ensure size/surface-dependent particle effects for specific applications. In the case of nanoparticle research, pre-treatments for dispersing solids include hot air oxidation, application of ozone, deep-freezing below $195^{\circ} \mathrm{C}$ and the use of chemical stabilizers [22-24].

Ultrasonic treatment is also commonly used in this field, as it is reported to break down agglomerates in the nanoscale [25]. Acoustic cavitation as the main process leads to deagglomeration and formation of $\mathrm{OH}$-radicals with temperatures of up to $5000 \mathrm{~K}$ and pressures of $1000 \mathrm{~atm}$ after bubble collapse. Cavitation and cavitation-induced shockwaves accelerate particles in dispersion which will eventually collide. These interparticle collisions can change the surface morphology, composition and reactivity [26]. Sonochemistry, therefore, offers interesting possibilities to stabilize MP dispersions through a combination of physical and chemical interactions.

A stable and fully dispersed dispersion is characterized by stronger repulsive forces which kinetically hinder the non-equilibrium state to reach equilibrium in an agglomerated state [6]. So, either the net forces in the dispersion have to be measured or the state of particles (isolated or agglomerated) has to be monitored. In many studies, scanning electron microscopy (SEM) images are provided to characterize particles used for dispersions [8]. Static imaging, however, may not be suitable since particles are removed from the test matrix (usually water), dried and further prepared (e.g., sputtered with gold) to meet prerequisites of the imaging process. SEM images still give valuable insights concerning particle size and morphology [27].

Zeta potential measurements are widely used to study the effects of ion strength, $\mathrm{pH}$ and humic substances on the stability of MP and nanoplastic (NP) dispersions [12,13,15,16]. This parameter is essential to characterize dispersions, but measurements are elaborate and time-consuming and limited 
to smaller particle sizes depending on the density of the particle. Particle concentration measurements, on the other hand, are fast and can give an insight into the size distribution of a polydisperse system. Through the simple measurement of light extinction, the particle concentration can be determined directly in the liquid as an index of dispersibility. The number of particles per unit volume combined with size measurements are good indicators for the state of a dispersion [21].

In this work, we evaluated additive-free methods of dispersion for cryomilled PS particles. For this purpose, manual shaking by hand, long-term horizontal shaking and ultrasonic treatment were compared regarding the suitability of dispersing particles, and the effects on particle numbers and size fractions were investigated. Light extinction measurements were used as a quality indicator for the degree of dispersion. By volume calculation of dispersed particles, the dispersion efficiency $E_{D}$ was determined to evaluate the methods of dispersing.

\section{Materials and Methods}

PS particles were produced by cryogenic ball milling (Cryomill, Retsch, Germany) of pristine PS pellets (BASF, Ludwigshafen, Germany). The procedure was previously documented in detail [5]. The PS powder was then dry-sieved over a $100 \mu \mathrm{m}$ stainless steel mesh (Retsch, Haan, Germany) to exclude larger particles. Ultrapure water (ELGA, Celle, Germany) was used for all batches and cleaning steps. In this process, 500 and $1000 \mathrm{~mL}$ glass bottles (Schott, Mainz, Germany) were used for the preparation of the batches. Thorough cleaning of all glassware was achieved by multiple washing, including the use of detergent and ultrasonic baths.

PS particle batches were prepared by weighing-in with a lab scale (A200S, Sartorius, Germany) using an anti-static gun and carefully rinsing the particles into the bottles. Ultrapure water was added by weight to obtain a particle concentration of $20 \mathrm{mg} / \mathrm{L}$ PS particles. Three different treatment approaches were used to disperse the hydrophobic PS particles: manual shaking by hand, automated shaking on a horizontal shaker and ultrasonic treatment.

Manual shaking was continuously done by hand with a consistent movement so that the water-gas interface was disrupted. Each up and down movement of the bottle was counted as one agitation. Particle measurements were made every 50 agitations up to a total of 250 agitations.

A horizontal shaker was used at 250 rounds per minute for automated shaking. Initially, the batches were measured every 60-80 $\mathrm{min}$, and this interval was increased throughout the experiment for, in total, $754 \mathrm{~h}$ to fully evaluate the impact of long-term agitation.

Ultrasonic treatment was done in an ultrasonic bath (Sonorex Super RK 106, Bandelin, Germany) with a rated output of $120 \mathrm{~W}$, and a frequency of $35 \mathrm{kHz}$ was applied in 5-15 min intervals. Bottles were submerged in a deionized/tap water mixture to approximately $2 / 3$ of the height. The uniformity of the ultrasonic field was not tested.

Particle size and number was determined by light extinction measurement using a particle counter (SVSS, PAMAS, Rutesheim, Germany). For each measurement, $3 \mathrm{~mL}$ of the sample was analyzed and every sample was measured in triplicate (mean value is shown, error bars are provided). The particle counter groups detected particles into channels, the boundary settings for these channels are provided in the SI, Section D. Batches were slightly stirred before measurement to resuspend deposited particles and rinse-off particles attached to the upper part and neck of the bottles. Previous experiments showed that magnetic stir bars can increase particle concentration through abrasion of the bars or the bottle bottom, and were therefore not used. For the settling experiment, the batch was not shaken and only moved carefully for measurement purpose. All concentration values shown are averaged from 3 measurements, and no particle settling could be detected between triplicate measurements. Average particle diameter was about $3 \mu \mathrm{m}$ and differences in the densities of PS and water is low, therefore significant settling in the time frame of a measurement-(approximately 3 min for triplicate analyses)was not expected. As illustrated in Figure 1, the timespan of measurement is too small for a considerable settling process of particles expected in the size range of 1-20 $\mu \mathrm{m}$. 


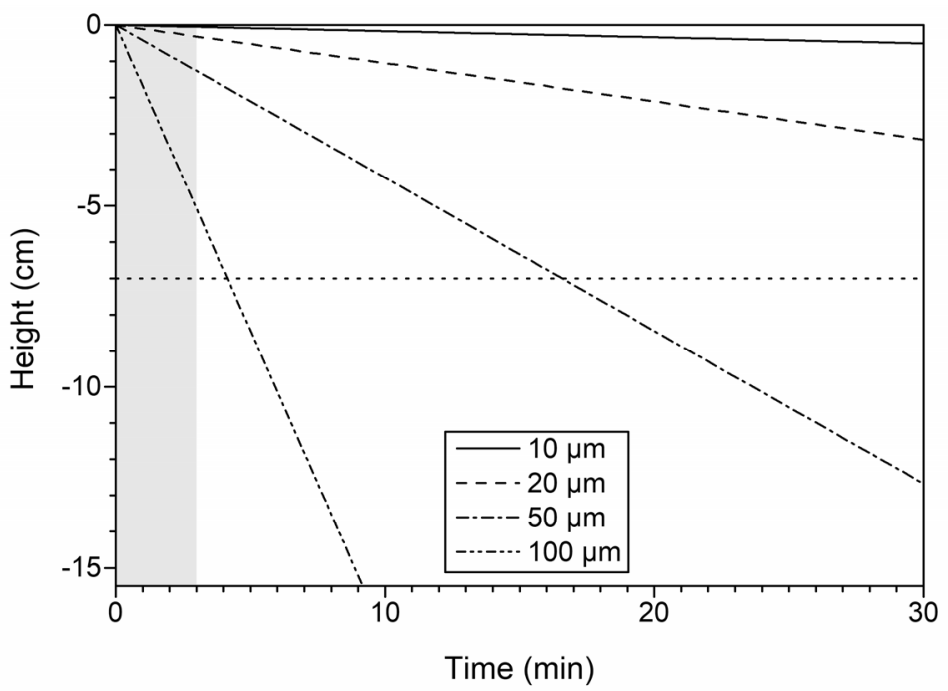

Figure 1. Theoretical position of an exemplary cryomilled polystyrene (PS) particle with a density of $1.05 \mathrm{~g} / \mathrm{cm}^{3}$ during settling in the course of a measurement with PAMAS particle counter. The particle starts to sink at the water level. Height $=0 \mathrm{~cm}$ : water level of glass bottle; height $=-15.5 \mathrm{~cm}$ : bottom of glass bottle. Full, dashed and dash-dotted lines: theoretical location of particles of different diameters. Horizontal dotted line: suction height of tubing connected to PAMAS device $7 \mathrm{~cm}$ from water surface. Highlighted area shows timespan of a measurement (less than $3 \mathrm{~min}$ ). Stoke's law with assumption of spherical shape was used for calculations.

The suspended solid volume of PS particles was calculated using particle size data with the lower channel boundary and using spherical shape (see SI, Section A). In a previous study, the irregular morphology of cryogenic milled PS powder was shown [5]. The lower channel boundaries were therefore used to partly compensate for the overestimation of volume by assuming a spherical shape of particles. In order to compare the preparation methods, the parameter dispersion efficiency $E_{D}$ was used (for formulae see SI, Section C). $E_{D}$ is the ratio between calculated suspended solid volume $V_{\text {css }}$ and theoretical suspended solid volume $\mathrm{V}_{\text {tss }}$ and indicates the state of the dispersion (fully dispersed vs. agglomerated/attached to surfaces etc.). $\mathrm{V}_{\text {tss }}$ was calculated using the suspended solid mass and a PS density of $1.05 \mathrm{~g} / \mathrm{cm}^{3}$. $V_{\text {css }}$ was calculated using the particle counter data and the lower channel boundary (see SI, Section D) and volume formula for spherical shape.

\section{Results}

\subsection{Horizontal Shaker vs. Ultrasonic Treatment}

A set of six identically prepared batches was placed on a horizontal shaker for $754 \mathrm{~h}$ and particle concentrations were repeatedly measured (Figure 2a). After $754 \mathrm{~h}$, the batches were treated ultrasonically twice for $15 \mathrm{~min}$. Initial particle concentrations varied between 27,000 and 33,000 1/mL and increased to a plateau of about 102,000-134,000 1/mL after $410 \mathrm{~h}$ (mean =120,000 1/mL, rel. SD =9.1\%). Additional horizontal shaking did not significantly increase particle numbers. Subsequent ultrasonic treatment, however, led to a further increase in particle numbers by $18 \%$ (mean $=143,0001 / \mathrm{mL})$ possibly due to deagglomeration of particles through higher shear forces compared to physical shaking. In addition, rel. SD decreased to $4.5 \%$, equalizing the batches. Mean $\mathrm{E}_{\mathrm{D}}$ after $754 \mathrm{~h}$ was $104 \%$, additional ultrasonic treatment decreased $\mathrm{E}_{\mathrm{D}}$ to $98 \%$. Long-term horizontal shaking only resulted in a partial deagglomeration. This has to be seen critically since usual contact times of adsorption experiments are in the magnitude of 48-72 $\mathrm{h}[28,29]$ with even less efficient dispersion. 


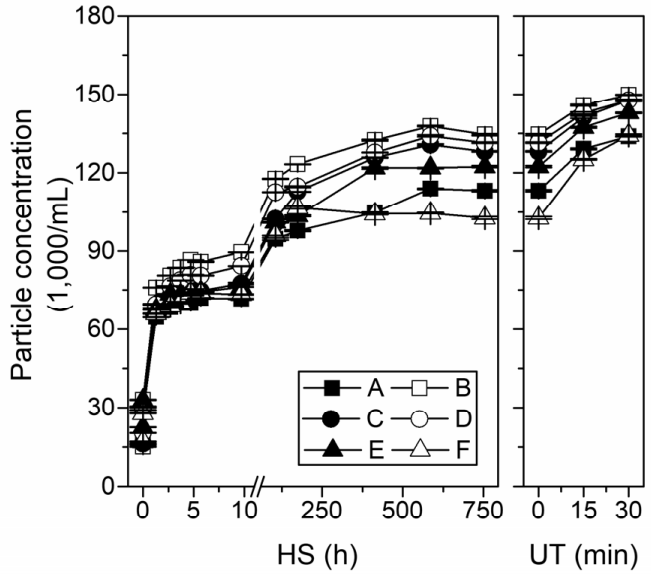

(a)

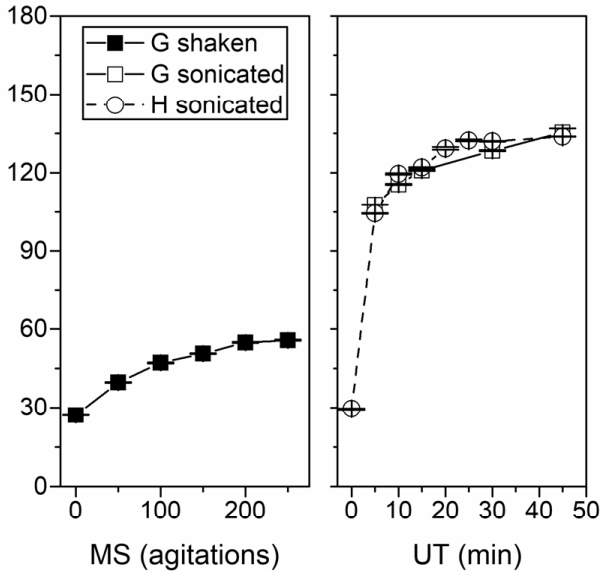

(b)

Figure 2. (a) Left: Particle concentration of six batches (20 mg/L PS particles) during 750 h horizontal shaking (HS). Right: Particle concentration of the same 6 batches during 30 min ultrasonic treatment (UT). (b) Particle concentrations of two batches (20 mg/L PS particles); batch G was manually shaken (MS) for 250 times (left diagram, full squares) and subsequently sonicated (right diagram, empty squares), batch $\mathrm{H}$ was directly sonicated (UT; right diagram, empty circles). Error bars show standard deviation of $n=3$.

\subsection{Manual Shaking vs. Ultrasonic Treatment}

To analyze the effect of manual shaking compared to sonication, two batches ( $20 \mathrm{mg} / \mathrm{L}$ PS) were prepared. Initial particle concentrations of both batches were $25,0001 / \mathrm{mL}$ after slight mixing. Batch $\mathrm{G}$ was then repeatedly shaken 50 times and measured up to 250 agitations (Figure $2 \mathrm{~b}$ left diagram, full squares), then sonicated for a total of $45 \mathrm{~min}$ (Figure $2 \mathrm{~b}$ right diagram, empty squares). Batch $\mathrm{H}$ (right diagram, empty circles) was directly sonicated without manual shaking.

Manual shaking of batch $\mathrm{G}$ reached 55,000 1/mL after 250 agitations with only a small increase in particle numbers. Sonication for $45 \mathrm{~min}$ increased particle concentration of batch $\mathrm{G}$ to $135,0001 / \mathrm{mL}$. After $45 \mathrm{~min}$ of sonication, batch $\mathrm{H}$ also reached a concentration of 133,000 1/mL. Manual shaking achieved an $\mathrm{E}_{\mathrm{D}}$ of $69 \%$ after 250 agitations. After ultrasonic treatment, batches $\mathrm{G}$ and $\mathrm{H}$ reached $E_{D}$ of $106 \%$ and $104 \%$, respectively. Almost complete dispersion was reached after 25 min of ultrasonic treatment. Measurements at ultrasonic durations of 5, 10, 15, and $30 \mathrm{~min}$ show that manual shaking before sonication did not improve dispersibility. The final particle concentrations of both batches are almost identical after sonication, showing the reproducibility of ultrasonic treatment. This strongly emphasizes that manual shaking only is not a sufficient way of dispersing particles that tend to agglomerate.

\subsection{Reproducibility of Ultrasonic Treatment}

Reproducibility of the dispersion preparation is an essential requirement. Therefore, a set of six batches (20 mg/L PS particles) was sonicated consecutively and particles were measured after every $15 \mathrm{~min}$ of treatment (Figure 3). Initial particle concentrations varied from 2600 to 6500 1/mL (mean $=48001 / \mathrm{mL}$, rel. SD $=26.4 \%$ ) without any treatment. Particle concentrations reached a mean of $120,0001 / \mathrm{mL}$ with rel. SD of $3.5 \%$ after $120 \mathrm{~min}$ of sonication. An additional relatively small increase to 126,000 1/mL occurred after treatment for $180 \mathrm{~min}$, indicating that ultrasonic treatment did not further erode particles. Ultrasonic treatment broke up agglomerates to a specific limit which is likely a function of applied power, as was suggested in another work [30]. This pre-treatment technique produced comparable dispersions, but attention has to be paid on the extent of interparticle bonding (which depends on material, size, shape and surface groups). In contrast to prior experiments, the discrepancy between the batches after $30 \mathrm{~min}$ is greater compared to the batch from Figure $2 \mathrm{~b}$ (right diagram) and full dispersibility was reached within $90-120 \mathrm{~min}$. The mean $\mathrm{E}_{\mathrm{D}}$ after $90-120 \mathrm{~min}$ was $125 \%$, which implies an overestimation of the suspended solid volume. 


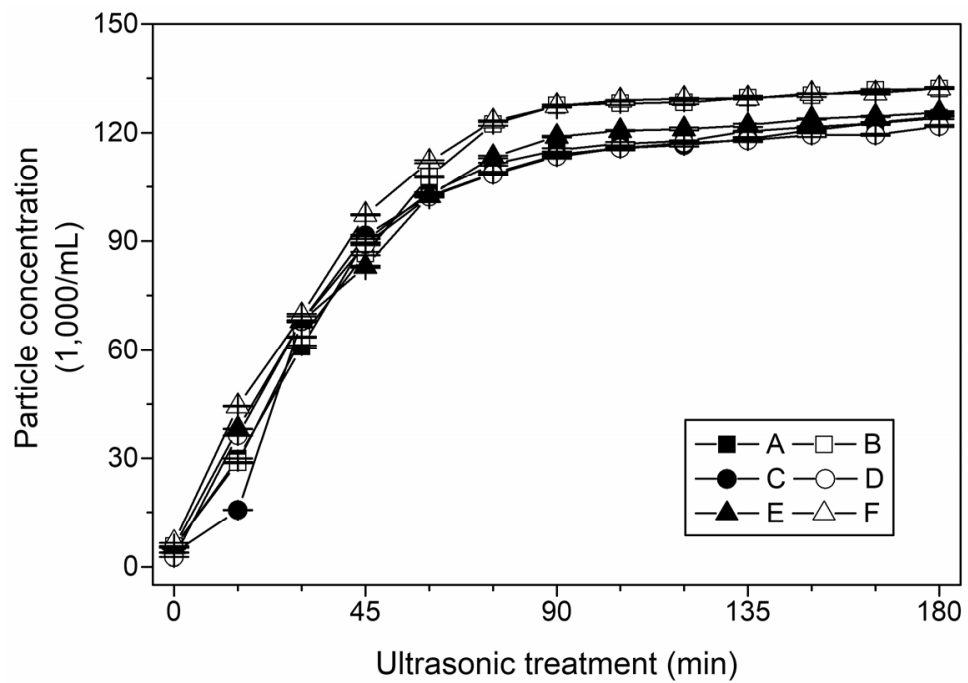

Figure 3. Particle concentrations of six batches (A-F $=20 \mathrm{mg} / \mathrm{L}$ PS particles) during ultrasonic treatment of $180 \mathrm{~min}$. Error bars show standard deviation of $\mathrm{n}=3$.

\subsection{Changes in Particle Size Distribution}

To identify changes in the particle composition through deagglomeration, the particles were grouped into the size fractions $<5,5-10$, and $>10 \mu \mathrm{m}$, since the majority of particles detected are well below $10 \mu \mathrm{m}$ in size. As can be seen from Figure 4a, physical agitation increased the particle numbers of all size fractions (data shown here are for batch A of the horizontal shaker experiment, but similar outcomes were achieved with all other batches). The increase in the size fraction $<5 \mu \mathrm{m}$ is considerably larger than in the other two size fractions and increased from around $63.5 \%$ after 100 agitations by manual shaking to $83.7 \%$ after $754 \mathrm{~h}$ automated shaking and $0.5 \mathrm{~h}$ ultrasonic treatment. The proportion of the fractions $5-10$ and $>10 \mu \mathrm{m}$ in size decreased from $22.0 \%$ and $14.5 \%$ to $12.6 \%$ and $3.7 \%$, respectively.

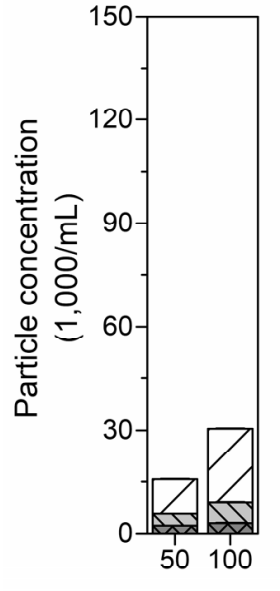

MS (agitations)

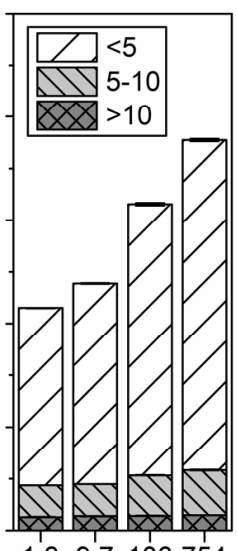

1.39 .7106754

HS (h)

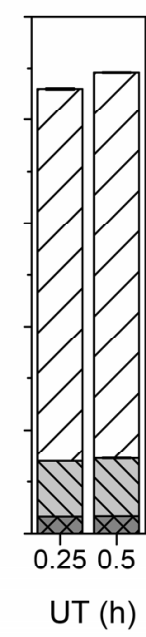

UT (h)

(a)

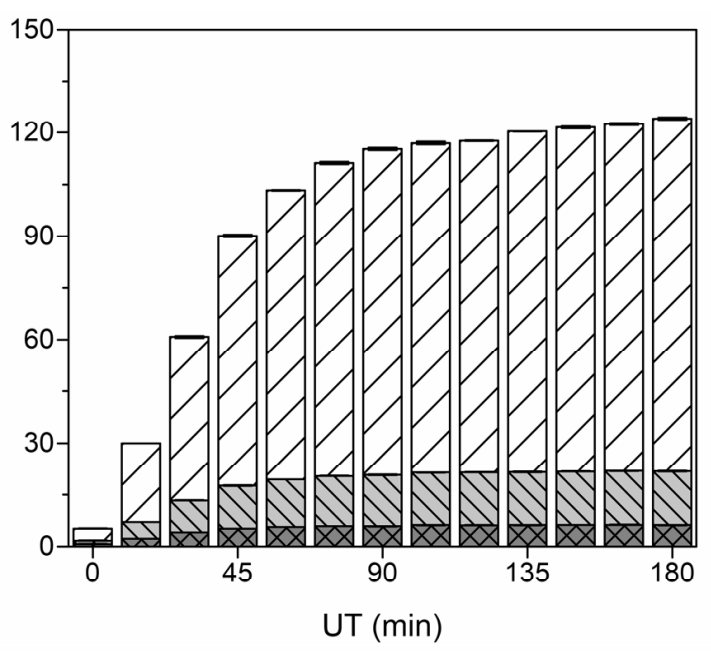

(b)

Figure 4. (a) Particle concentration of batch A during manual shaking (MS), horizontal shaking (HS) and ultrasonic treatment (UT). (b) Particle concentration of batch A (20 mg/L PS particles) during ultrasonic treatment (UT) for $180 \mathrm{~min}$. Particles in all diagrams were grouped in size fractions $<5 \mu \mathrm{m}$, $5-10 \mu \mathrm{m}$ and $>10 \mu \mathrm{m}$. Error bars show standard deviation of $\mathrm{n}=3$.

For sonication, the first minutes of ultrasonic treatment sufficed to increase numbers of dispersed particles and greatly change particle composition (Figure $4 \mathrm{~b}$, data shown for batch A). Particle numbers 
of the fractions $5-10 \mu \mathrm{m}$ and $>10 \mu \mathrm{m}$ did not further increase after 90 min of ultrasonic treatment, whereas a slight increase for the fraction $<5 \mu \mathrm{m}$ was observed.

Before ultrasonic treatment, the size fractions $<5,5-10$, and $>10 \mu \mathrm{m}$ made up $66.5 \%, 18.6 \%$ and $14.8 \%$ of all particles, respectively. After $30 \mathrm{~min}$, the size fraction ratios changed to $78.1 \%, 15.2 \%$, and $6.7 \%$ for $<5,5-10$, and $>10 \mu \mathrm{m}$, respectively. Subsequent ultrasonic treatment increased the number of particles but only led to minor changes in the size composition. The size fractions after $180 \mathrm{~min}$ ultrasonic were $82.5 \%, 12.5 \%$, and $5.0 \%$ for $<5,5-10$, and $>10 \mu \mathrm{m}$, respectively. In terms of dispersion characterization, horizontal shaking and sonication lead to a similar dispersion composition (see Figure $4 a, b)$. The initial increase in particle concentrations was caused by deagglomeration of larger particles with weak coherence and the number of particles of fraction $<5 \mu \mathrm{m}$ increased, whereas particle numbers of the two larger fractions decreased with increasing treatment time. Further disintegration of larger particles or agglomerates could not be shown since the number of larger particles/agglomerates (fraction $>10 \mu \mathrm{m}$ ) remained constant. This is in accordance with Meissner et al. [31], who reported no further deagglomeration/disintegration visible after thorough sonication of carbide nanoparticles.

\subsection{Changes in Calculated Volume Distribution during Ultrasonic Treatment}

As additional criteria for dispersion efficiency, suspended solid volumes were calculated from particle numbers of each measurement channel. After $90 \mathrm{~min}$ of sonification, the calculated volume did not further increase (Figure 5a). However, values from 90 to $180 \mathrm{~min}$ are scattered due to a few larger particles still present in the batch which greatly affected the total calculated volume (which can also be seen in Figure 6). The calculated particle volume of sonicated samples from ultrasonic experiments increased to a mean of $24.1 \times 10^{6} \mathrm{\mu m}^{3} / \mathrm{mL}$ (calculated from values 120-180 min) with rel. SD of 3.2\%, whereas the total theoretical suspended volume of the PS is $19.6 \times 10^{6} \mu \mathrm{m}^{3} / \mathrm{mL}$. $\mathrm{E}_{\mathrm{D}}$ calculated with the mean volume of $120-180$ min was therefore $127 \%$, which indicates that calculation of the volume overestimated the volume in dispersion.

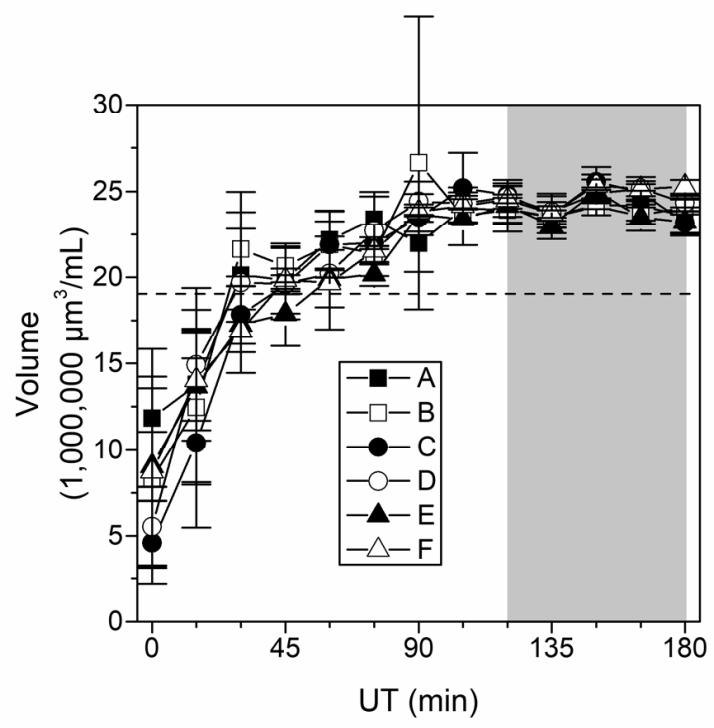

(a)

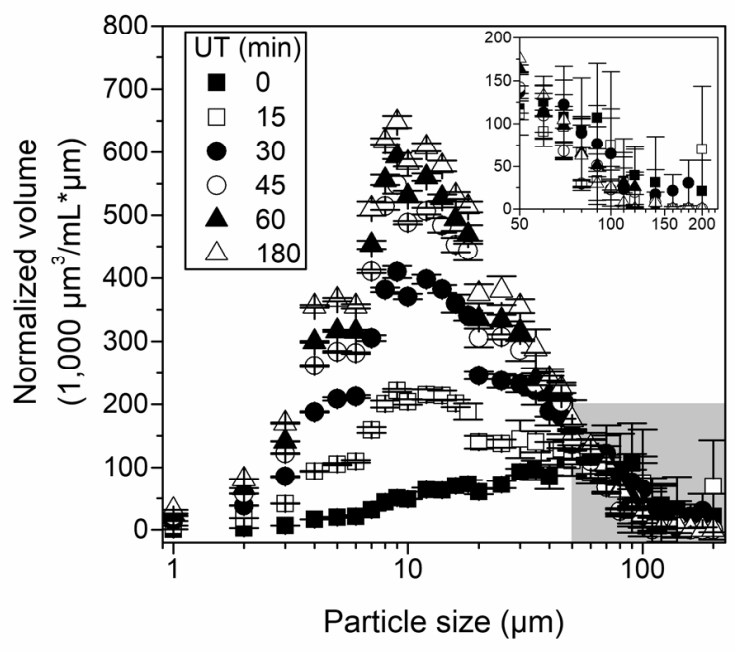

(b)

Figure 5. (a) Calculated suspended solid volume of six batches (A-F $=20 \mathrm{mg} / \mathrm{L}$ PS particles) during ultrasonic treatment (UT). Dotted line at $19,048,000 \mu \mathrm{m}^{3} / \mathrm{mL}$ indicates an $\mathrm{E}_{\mathrm{D}}$ of $100 \%$. Highlighted area was used for calculation of mean volume and $E_{D}$. (b) Calculated volume per size channel of batch $A$ during 180 min of ultrasonic treatment. Values were normalized through division by channel width to compare smaller and larger channels. A non-normalized graph can be found in the SI, Figure S2. Error bars show standard deviation of $n=3$. 


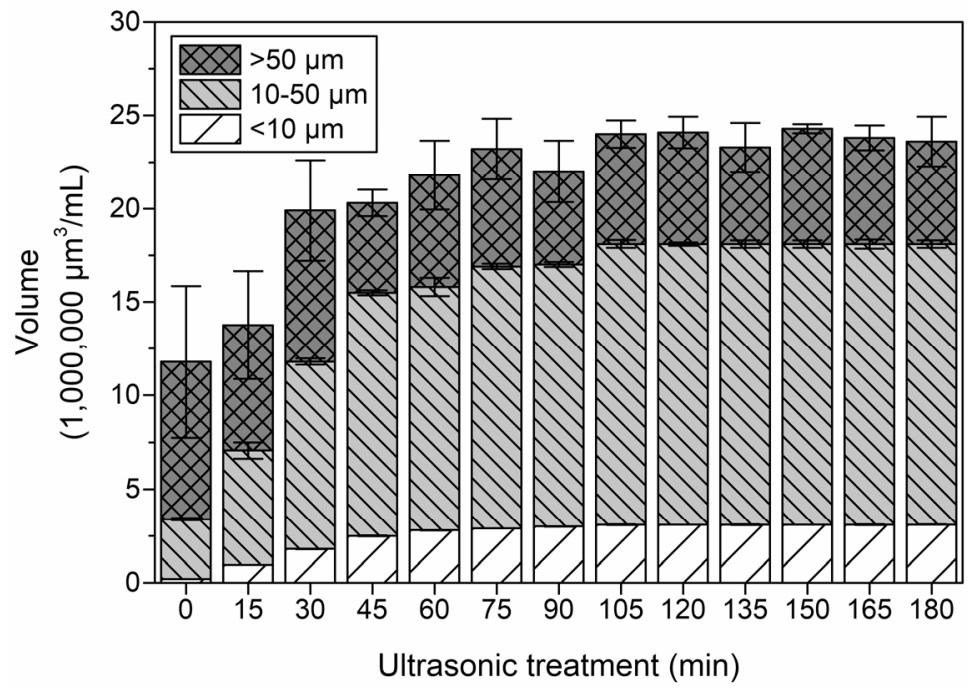

Figure 6. Calculated volume of batch A during ultrasonic treatment. Particles were grouped in size fractions $<10,10-50$, and $>50 \mu \mathrm{m}$ (please note: different fractions were chosen for volume fractions compared to number fractions). Error bars show standard deviation of $n=3$.

To identify the cause of the increase in total suspended solid volume, the contributing volume of each measurement channel is shown in Figure $5 \mathrm{~b}$. All channels up to $50 \mu \mathrm{m}$ contribute to the increase in total volume of $180 \mathrm{~min}$ of ultrasonic compared to the distribution after $15 \mathrm{~min}$ of ultrasonic treatment. A decrease in the volumes of particles $>50 \mu \mathrm{m}$ can be noted with prolonged treatment (see inset diagram). Since total volume of particles $<50 \mu \mathrm{m}$ increased it can be concluded that breakdown of larger particles occurred mostly for particles $>50 \mu \mathrm{m}$.

To further elucidate the changes in volume, Figure 6 shows the volume of batch A during ultrasonic treatment of 180 min grouped into three size fractions, $<10,10-50$, and $>50 \mu \mathrm{m}$. The untreated sample had a low initial volume which increased with further treatment. The fractions $<10$ and $10-50 \mu \mathrm{m}$ increased from $1.6 \%$ and $27.4 \%$ of the total volume to a share of $13.3 \%$ and $63.4 \%$, respectively, whereas the fraction $>50 \mu \mathrm{m}$ decreased from $70.9 \%$ to $23.3 \%$, as was mentioned before. Size fraction $<10 \mu \mathrm{m}$ remained relatively constant after $60 \mathrm{~min}$ of treatment, and size fraction 10-50 $\mu \mathrm{m}$ remained constant after $105 \mathrm{~min}$. The volume of particles $>50 \mu \mathrm{m}$, however, showed strong fluctuation over the whole treatment duration. These larger particles/agglomerates were not disintegrated with ultrasonic treatment, explaining the fluctuations in total calculated volume.

\subsection{Settling of Particles after Ultrasonic Treatment}

Small particles of a fully dispersed solution should follow Stoke's law for settling and not re-agglomerate over time. Therefore, the settling behavior of a dispersion $(20 \mathrm{mg} / \mathrm{L}$ PS particles, 180 min sonicated) was monitored for one week (SI, Figure S3). Particle concentration decreased from $173,0001 / \mathrm{mL}$ to $124,0001 / \mathrm{mL}$ over $168 \mathrm{~h}$ ( $=30 \%$ decrease). Settling was the main process of particle loss and, as expected, larger particles $>10 \mu \mathrm{m}$ settled faster and were not present in the dispersion anymore after $168 \mathrm{~h}$ (SI, Figure S4). Interestingly, particles of $3 \mu \mathrm{m}$ diameter or larger should have settled after this time according to Stoke's law-however, still $20 \%$ of all particles were of this size category (data not shown). No agglomeration could be monitored since volume of all size fractions decreased over time (SI, Figure S5).

\subsection{Environmental Implications}

Virgin PS particles are hydrophobic and do not independently disperse in water. The experiments showed that an enormous energy input is needed to fully disperse virgin PS particles if no other processes such as biofilm formation, adsorption of organic matter or weathering are involved. Through this 
energy input, larger agglomerates broke up into smaller particles and the average particle size decreased. Particles were stabilized for more than $168 \mathrm{~h}$ and a fraction of particles between 3 and $10 \mu \mathrm{m}$ did not settle, contrary to calculations with Stoke's law.

\section{Discussion}

The aim of this study was to evaluate an additive-free method to disperse model MP particles in water to realistically depict concentration-effect relations of MP particles. Primary MP particles released into the environment most likely start out as a hardly dispersible material, as with the model particles used in this study, and the dispersion of these is still unknown. Therefore, the preparation of these virgin MP particle dispersions for laboratory studies is important to understand the behavior and fate of virgin MP particles in the environment. Using ultrasonic pre-treatment for cryomilled pristine polystyrene particles, reproducible dispersions of $20 \mathrm{mg}$ suspended solid per liter were obtained. The physical particle interactions induced by the ultrasonic bath after 90 min effectively dispersed particles, while no substantial increase in dispersed particle numbers was observed with longer treatment. With further sonication, the number of particles $>50 \mu \mathrm{m}$ fluctuated while particle numbers $<50 \mu \mathrm{m}$ remained constant, showing that ultrasonic treatment did not further disintegrate PS particles. Ultrasonic treatment as a dispersion technique thus increased the numbers of particles in the dispersion and ensured the availability of particles for possible interaction. After $24 \mathrm{~h}$, around $70 \%$ of the particles of a dispersion (180 min of ultrasonic treatment) were still in dispersion.

In contrast to ultrasonic treatment, long-term horizontal shaking and manual shaking did not suffice for fully dispersing all particles. Dispersion efficiency was 127\%, 104\%, and 69\% for ultrasonic treatment (180 $\mathrm{min})$, long-term horizontal shaking (754 h) and manual shaking (250 agitations), respectively. This is in accordance with a similar study implementing nanosized silica and alumina particles in which ultrasonic homogenization as well as stirred media milling proved most effective for deagglomeration [32]. $\mathrm{E}_{\mathrm{D}}$ values of above $100 \%$ indicated that the presumption of spherical shape for cryogenically produced particles is a simplification, as cryomilled particles are more shard-like fragments [5]. This overestimated the calculated volume of measured particles when using the Feret diameter given by the particle counter, which was only partly counteracted by using the lower boundaries of the measurement channels.

Using alkaline ultrasonic treatment van der Esch et al. [3] reported stable dispersions with aged MP but with a high variability (1,5 log-orders) in particle concentrations. For PS, the toxicologically interesting fraction $<20 \mu \mathrm{m}$ ranged from 40 to $80 \%$ within three replicates. This emphasizes the need for appropriate production of particles and pre-treatment for dispersions. Chung et al. [30] reported a maximum dispersing effect after 20-30 min for zinc oxide nanoparticles using ultrasonic baths. Although the materials and therefore binding forces are not directly comparable, a maximum was also found in this study for ultrasonic dispersion after $90 \mathrm{~min}$. Treatment times can possibly be shortened by using a higher input power; however, the potentially achievable deagglomeration is a function of output power of the ultrasonic device and two different ultrasonic devices need to be cautiously compared.

Van der Esch [3] reported eroded surfaces on $1 \mathrm{~cm}^{2}$ polystyrene squares cut from larger sheets and additional FTIR-bands mimicking weathering processes in the environment. We did not investigate changes in the morphology through radical attack during sonification. Such changes were not expected since the duration of ultrasonic treatment was much shorter (180 min compared to $15 \mathrm{~h}$ ) and $\mathrm{pH}$ (unbuffered) was around 5.5 (van der Esch: $\mathrm{pH}=13$ ). Therefore, surface oxidation during sonication in this study is unlikely. Nevertheless, it needs to be discussed whether polymers pre-treated in an ultrasonic bath even for short periods can still be regarded as pristine if the surface of particles is potentially altered.

Another challenge in dispersion preparation is the weighing-in: a precise execution is difficult due to fine powder in the $\mu \mathrm{m}$ area, low density materials and potential electrostatic forces. Air drafts and charged surfaces of laboratory equipment can easily carry away the finer fraction of polydisperse 
powders. The particle concentration of six batches of identical weight-in particles still showed a rel. SD of $3.5 \%$ after 180 min of ultrasonic treatment. We therefore suggest preparing a more concentrated dispersion which has to be thoroughly treated with ultrasound before further dilution to targeted concentrations.

Concerning the stability of dispersions, no agglomeration behavior could be observed in a dispersion after $168 \mathrm{~h}$. This was expected since larger particles settled quickly while smaller particles apparently remained as single particles in dispersion. Settling could have been disturbed by the high number of particles in dispersion, this would explain particles of the size 3-10 $\mu \mathrm{m}$ still present in the water column after $168 \mathrm{~h}$. The settling of irregularly shaped particles does not necessarily follow Stoke's law applied on spherically shaped objects, as is the case for natural colloid aggregates [33]. Ultrasound treatment is therefore suitable for pre-treatment of PS particle dispersions for eco-toxicological studies since the stabilized particles are available for possible ingestion by aquatic species. Nevertheless, the results point out the reluctance of microplastic particles to behave as predicted by models-in laboratory studies as well as in environmental sampling.

Delmas and Barthe [34] claimed that addition of surfactant for stabilization is still required after the use of ultrasound to stop agglomeration; however, this type of interparticle bonding is weaker after ultrasonic treatment rendering the use of surfactant more effective. Whether the use of surfactant is still required needs to be decided depending on the experiment. The time-dependent stability of dispersions (the tendency to agglomerate) has to be evaluated individually for each experimental setup since particle size and surface chemistry are key factors in agglomeration processes. This is an important issue for toxicological studies as well as the transport behavior of particles during experiments. Regarding a potential stability of over $168 \mathrm{~h}$ through ultrasonic treatment, we do not suggest the use of surfactants for microplastic experiments due to possible side-effects, as stated above by some other authors.

In the environment, the dispersion of virgin MP particles through energy input could be achieved by strong currents and turbulence in rivers and other surface waters. Other processes influencing the stabilization of virgin MP particles in natural environment include biofilm formation, adsorption of organic substances and weathering. Once stabilized, these particles are mobile and do not necessarily settle according to model calculations. As a consequence, MP particles are found throughout the water column and not only in the sediment, aggravating possible remediation techniques. The removal of virgin MP in wastewater treatment plants thus seems to depend on inclusion in flocs or foams. Further research needs to focus on the concurrence of environmental processes contributing to the stabilization of virgin MP particles and the resulting behavior in water to evaluate target-oriented measures to remove MP particles from the environment.

This study provides valuable insights for research groups working with model suspensions. Basic understanding of the behavior of model particles in aqueous suspensions is one of the pre-requisites for systematic research and the transfer of laboratory investigations to environmental research outcomes.

Supplementary Materials: The following are available online at http://www.mdpi.com/2073-4441/12/12/3436/s1, Figure S1: Calculated volume of six batches (A-F) of $20 \mathrm{mg} / \mathrm{L}$ polystyrene particles during ultrasonic treatment. Batches were repeatedly placed for $15 \mathrm{~min}$ in ultrasonic bath and particle numbers measured through light extinction; Figure S2. Calculated volume per size channel of batch ' $\mathrm{A}$ ' during $180 \mathrm{~min}$ of ultrasonic treatment. Values were non-normalized compared to Figure 5b; Figure S3. Particle settling of a $20 \mathrm{mg} / \mathrm{L}$ polystyrene dispersion which was left to settle for one week and only moved for measuring purpose. Inlay shows particle concentration during the first two hours. Dispersion was prepared with $180 \mathrm{~min}$ of ultrasonic treatment. Sample was measured in triplicate; Figure S4. Size fractions of long-term particle settling dispersion ( $20 \mathrm{mg} / \mathrm{L}$ polystyrene) with $180 \mathrm{~min}$ of ultrasonic treatment. Sample was measured in triplicate; Figure S5. Calculated volume of a long-term particle settling dispersion $(20 \mathrm{mg} / \mathrm{L}$ polystyrene) up to $180 \mathrm{~min}$ of ultrasonic treatment. Sample was measured in triplicate.

Author Contributions: The article was written by L.E. within his project, with supervision by A.S.R. and M.J. All authors have read and agreed to the published version of the manuscript.

Funding: This research received no external funding. 
Acknowledgments: We acknowledge support by the German Research Foundation and the Open Access Publication Fund of TU Berlin.

Conflicts of Interest: The authors declare no conflict of interest. The funders had no role in the design of the study; in the collection, analyses, or interpretation of data; in the writing of the manuscript, or in the decision to publish the results.

\section{References}

1. Connors, K.A.; Dyer, S.D.; Belanger, S.E. Advancing the quality of environmental microplastic research. Environ. Toxicol. Chem. 2017, 36, 1697-1703. [CrossRef] [PubMed]

2. Potthoff, A.; Oelschlägel, K.; Schmitt-Jansen, M.; Rummel, C.D.; Kühnel, D. From the sea to the laboratory: Characterization of microplastic as prerequisite for the assessment of ecotoxicological impact. Integr. Environ. Assess. Manag. 2017, 13, 500-504. [CrossRef] [PubMed]

3. Von der Esch, E.; Lanzinger, M.; Kohles, A.J.; Schwaferts, C.; Weisser, J.; Hofmann, T.; Glas, K.; Elsner, M.; Ivleva, N.P. Simple Generation of Suspensible Secondary Microplastic Reference Particles via Ultrasound Treatment. Front. Chem. 2020, 8, 169. [CrossRef] [PubMed]

4. Waldman, W.R.; Rillig, M.C. Microplastic Research Should Embrace the Complexity of Secondary Particles. Environ. Sci. Technol. 2020, 54, 7751-7753. [CrossRef] [PubMed]

5. Eitzen, L.; Paul, S.; Braun, U.; Altmann, K.; Jekel, M.; Ruhl, A.S. The challenge in preparing particle suspensions for aquatic microplastic research. Environ. Res. 2019, 168, 490-495. [CrossRef] [PubMed]

6. OECD. Test No. 318: Dispersion Stability of Nanomaterials in Simulated Environmental Media: OECD Guidelines for the Testing of Chemicals, Section 3; OECD: Paris, France, 2017. [CrossRef]

7. Fernández, B.; Albentosa, M. Dynamic of small polyethylene microplastics $(\leq 10 \mu \mathrm{m})$ in mussel's tissues. Mar. Pollut. Bull. 2019, 146, 493-501. [CrossRef] [PubMed]

8. Shams, M.; Alam, I.; Chowdhury, I. Aggregation and stability of nanoscale plastics in aquatic environment. Water Res. 2020, 171, 115401. [CrossRef]

9. Ateia, M.; Zheng, T.; Calace, S.; Tharayil, N.; Pilla, S.; Karanfil, T. Sorption behavior of real microplastics (MPs): Insights for organic micropollutants adsorption on a large set of well-characterized MPs. Sci. Total Environ. 2020, 720, 137634. [CrossRef]

10. Renzi, M.; Grazioli, E.; Blašković, A. Effects of Different Microplastic Types and Surfactant-Microplastic Mixtures Under Fasting and Feeding Conditions: A Case Study on Daphnia magna. Bull. Environ. Contam. Toxicol. 2019, 103, 367-373. [CrossRef]

11. Xia, Y.; Zhou, J.-J.; Gong, Y.-Y.; Li, Z.-J.; Zeng, E.Y. Strong influence of surfactants on virgin hydrophobic microplastics adsorbing ionic organic pollutants. Environ. Pollut. 2020, 265, 115061. [CrossRef]

12. Lu, S.; Zhu, K.; Song, W.; Song, G.; Chen, D.; Hayat, T.; Alharbi, N.S.; Chen, C.; Sun, Y. Impact of water chemistry on surface charge and aggregation of polystyrene microspheres suspensions. Sci. Total Environ. 2018, 630, 951-959. [CrossRef] [PubMed]

13. Li, S.; Liu, H.; Gao, R.; Abdurahman, A.; Dai, J.; Zeng, F. Aggregation kinetics of microplastics in aquatic environment: Complex roles of electrolytes, $\mathrm{pH}$, and natural organic matter. Environ. Pollut. 2018, 237, 126-132. [CrossRef] [PubMed]

14. Gao, Y.; Ren, X.; Tan, X.; Hayat, T.; Alsaedi, A.; Chen, C. Insights into key factors controlling GO stability in natural surface waters. J. Hazard. Mater. 2017, 335, 56-65. [CrossRef] [PubMed]

15. Tallec, K.; Blard, O.; González-Fernández, C.; Brotons, G.; Berchel, M.; Soudant, P.; Huvet, A.; Paul-Pont, I. Surface functionalization determines behavior of nanoplastic solutions in model aquatic environments. Chemosphere 2019, 225, 639-646. [CrossRef] [PubMed]

16. Cai, L.; Hu, L.; Shi, H.; Ye, J.; Zhang, Y.; Kim, H. Effects of inorganic ions and natural organic matter on the aggregation of nanoplastics. Chemosphere 2018, 197, 142-151. [CrossRef] [PubMed]

17. Liu, P.; Zhan, X.; Wu, X.; Li, J.; Wang, H.; Gao, S. Effect of weathering on environmental behavior of microplastics: Properties, sorption and potential risks. Chemosphere 2020, 242, 125193. [CrossRef]

18. Ter Halle, A.; Ladirat, L.; Martignac, M.; Mingotaud, A.F.; Boyron, O.; Perez, E. To what extent are microplastics from the open ocean weathered? Environ. Pollut. 2017, 227, 167-174. [CrossRef]

19. Labille, J.; Brant, J. Stability of nanoparticles in water. Nanomedicine 2010, 5, 985-998. [CrossRef] 
20. Keller, A.A.; Wang, H.; Zhou, D.; Lenihan, H.S.; Cherr, G.; Cardinale, B.J.; Miller, R.; Ji, Z. Stability and aggregation of metal oxide nanoparticles in natural aqueous matrices. Environ. Sci. Technol. 2010, 44, 1962-1967. [CrossRef]

21. Tantra, R.; Jing, S.; Pichaimuthu, S.K.; Walker, N.; Noble, J.; Hackley, V.A. Dispersion stability of nanoparticles in ecotoxicological investigations: The need for adequate measurement tools. J. Nanopart. Res. 2011, 13, 3765-3780. [CrossRef]

22. Ivanov, M.G.; Ivanov, D.M. Nanodiamond Nanoparticles as Additives to Lubricants. In Ultananocrystalline Diamond; Elsevier: Amsterdam, The Netherlands, 2012; pp. 457-492, ISBN 9781437734652.

23. Ozawa, M.; Inaguma, M.; Takahashi, M.; Kataoka, F.; Krüger, A.; Ōsawa, E. Preparation and Behavior of Brownish, Clear Nanodiamond Colloids. Adv. Mater. 2007, 19, 1201-1206. [CrossRef]

24. Schrand, A.M.; Hens, S.A.C.; Shenderova, O.A. Nanodiamond Particles: Properties and Perspectives for Bioapplications. Crit. Rev. Solid State Mater. Sci. 2009, 34, 18-74. [CrossRef]

25. Hwang, Y.; Lee, J.-K.; Lee, J.-K.; Jeong, Y.-M.; Cheong, S.; Ahn, Y.-C.; Kim, S.H. Production and dispersion stability of nanoparticles in nanofluids. Powder Technol. 2008, 186, 145-153. [CrossRef]

26. Suslick, K.S.; Price, G.J. Applications of Ultrasound to Materials Chemistry. Annu. Rev. Mater. Sci. 1999, 29, 295-326. [CrossRef]

27. Cole, M.; Galloway, T.S. Ingestion of Nanoplastics and Microplastics by Pacific Oyster Larvae. Environ. Sci. Technol. 2015, 49, 14625-14632. [CrossRef]

28. Abdurahman, A.; Cui, K.; Wu, J.; Li, S.; Gao, R.; Dai, J.; Liang, W.; Zeng, F. Adsorption of dissolved organic matter (DOM) on polystyrene microplastics in aquatic environments: Kinetic, isotherm and site energy distribution analysis. Ecotoxicol. Environ. Saf. 2020, 198, 110658. [CrossRef]

29. Bakir, A.; Rowland, S.J.; Thompson, R.C. Competitive sorption of persistent organic pollutants onto microplastics in the marine environment. Mar. Pollut. Bull. 2012, 64, 2782-2789. [CrossRef]

30. Chung, S.J.; Leonard, J.P.; Nettleship, I.; Lee, J.K.; Soong, Y.; Martello, D.V.; Chyu, M.K. Characterization of ZnO nanoparticle suspension in water: Effectiveness of ultrasonic dispersion. Powder Technol. 2009, 194, 75-80. [CrossRef]

31. Meißner, T.; Kühnel, D.; Busch, W.; Oswald, S.; Richter, V.; Michaelis, A.; Schirmer, K.; Potthoff, A. Physical-chemical characterization of tungsten carbide nanoparticles as a basis for toxicological investigations. Nanotoxicology 2010, 4, 196-206. [CrossRef]

32. Schilde, C.; Mages-Sauter, C.; Kwade, A.; Schuchmann, H.P. Efficiency of different dispersing devices for dispersing nanosized silica and alumina. Powder Technol. 2011, 207, 353-361. [CrossRef]

33. Baalousha, M.; Lead, J.R.; Ju-Nam, Y. Natural Colloids and Manufactured Nanoparticles in Aquatic and Terrestrial Systems. In Treatise on Water Science; Elsevier: Amsterdam, The Netherlands, 2011; pp. 89-129, ISBN 9780444531995.

34. Delmas, H.; Barthe, L. Ultrasonic mixing, homogenization, and emulsification in food processing and other applications. In Power Ultrasonics; Elsevier: Amsterdam, The Netherlands, 2015; pp. 757-791, ISBN 9781782420286.

Publisher's Note: MDPI stays neutral with regard to jurisdictional claims in published maps and institutional affiliations.

(C) 2020 by the authors. Licensee MDPI, Basel, Switzerland. This article is an open access article distributed under the terms and conditions of the Creative Commons Attribution (CC BY) license (http://creativecommons.org/licenses/by/4.0/). 